\title{
THE ATTITUDES OF TURKISH TRADESMEN TOWARDS SYRIAN REFUGEE TRADESMEN: A RESEARCH IN MERSIN
}

\author{
DOI: 10.17261/Pressacademia.2018.918 \\ PAP- V.7-2018(71)-p.367-371
}

\section{Aysehan Cakici ${ }^{1}$, Senay Yilmaz ${ }^{2}$, A. Celil Cakici ${ }^{3}$}

${ }^{1}$ Mersin Üniversitesi, iiBF, İ̧̧letme Bölümü, Çiftlikköy Kampusu, Yenişehir, Mersin, Turkey. aysehancakici@mersin.edu.tr, ORCID: 0000-0003-4090-5309

${ }^{2}$ Mersin Üniversitesi, SBE, İşletme Ana bilim dalı, Çiftlikköy Kampusu, Yenişehir, Mersin, Turkey. sen.ay.ylmz@outlook.com, ORCID: 0000-0002-7930-5143

${ }^{3}$ Mersin Üniversitesi, Turizm Fakültesi Turizm İşletmeciliği, Çiftlikköy Kampusu, Yenişehir, Mersin, Turkey. celilcakici@mersin.edu.tr, ORCID: 0000-0002-9192-1969

\section{To cite this document}

Cakici, A., Yilmaz, S., Cakici, A. C. (2018). The attitudes of Turkish tradesmen towards Syrian refugee tradesmen: a research in Mersin. PressAcademia Procedia (PAP), V.7, p.367-371.

Permemant link to this document: http://doi.org/10.17261/Pressacademia.2018.918

Copyright: Published by PressAcademia and limited licenced re-use rights only.

\section{ABSTRACT}

Purpose- The purpose of this research is to determine the attitudes and thoughts of Turkish tradesmen operating in Mersin towards Syrian tradesmen.

Methodology- The interview form used for data collection was applied based on purposive sampling method. 213 interviews were held between April and June of 2017 with Turkish tradesmen operating in places where Syrian refugee tradesmen were highly concentrated. The data obtained from open-ended questions were subjected to content analysis.

Findings- The majority of Turkish tradesmen have negative attitudes towards establishing business of Syrian tradesmen and think that they create a disadvantage for them. Being unregistered and creating unfair competition were accepted as the most reasons.

Conclusion- It was determined that Turkish tradesmen were disturbed by Syrian refugee tradesmen and had a negative attitude towards them. Operation without any registration, the government's privileged treats and unfaircompetition have been identified as important reasons.

Keywords: Turkish tradesmen, Syrian refugee tradesman, tradesmen attitude, Mersin.

JEL Codes: D22, J15, M10

\section{TÜRK ESNAFIN SURIYELI MÜLTECI ESNAF HAKKINDAKI TUTUMU: MERSIN'DE BIRR ARAŞTIRMA}

\section{ÖZET}

Amaç- Araştırmanın amacı, Mersinde faaliyet gösteren Türk esnafların Suriyeli esnaflar hakkındaki düşünceleri ve tutumunu belirlemektir. Yöntem- Veri toplanmasında kullanılan görüşme formu, amaçlı örnekleme metoduna göre uygulanmıştır. Suriyeli mülteci esnafların oldukça yoğun olduğu yerlerde faaliyet gösteren Türk esnaflarla 2017 yılı Nisan-Haziran ayları arasında 213 görüşme gerçekleştirilmiştir. Açık uçlu sorulardan elde edilen verilere içerik analizi uygulanmıştır.

Bulgular- Türk esnafın çoğunluğu, Suriyeli esnafın iş kurmalarına olumsuz bakmakta ve kendileri için dezavantaj yarattığını düşünmektedir. Kayıt dışı iş kurmaları, vergi vermemeleri ve haksız rekabet yaratmaları en önemli neden olarak belirtilmektedir.

Sonuç- Türk esnafların Suriyeli mülteci esnaflardan rahatsızlık duydukları ve olumsuz bir tutuma sahip oldukları belirlenmiştir. Kayıt dışılık, devletin imtiyazlı davranması ve haksız rekabet önemli gerekçeler olarak saptanmıştır.

AnahtarKelimeler: Türk esnaf, Suriyeli mülteci esnaf, esnaf tutumu, Mersin.

JEL Kodları: D22, J15, M10 


\section{Giriş}

Suriye iç savaşı, Ortadoğu coğrafyası tarihinde en karmaşık denklemli iç savaşlardan biridir. Bu savaş, sebep olduğu 4,9 milyon insanın ülke dışında sığınmacı konumuna düşürmüştür. Birleşmiş Milletler Mülteciler Yüksek Komiserliği rakamlarına göre Haziran 2016 itibariyle Türkiye'deki toplam Suriyeli sığınmacı sayısı 2.7 milyondan fazla olup, 1.6 milyonu çalışma çağındadır. AFAD verilerine göre, bunun \%10'luk dilimi geçici barınma merkezlerindedir. \%90'ı, başta sınıra yakın iller olmak üzere ülkedeki birçok kent ve kasabaya yerleşmişlerdir (ILO,2016; Çetin, 2017: 1002). Bunların bir kısmı inşaat, tekstil ve mevsimlik tarım iş̧̧isi olarak bağımlı işlerde çalışırken küçük bir kısmı da ticari ve sınai şirketler kurarak bağımsız işlerde çalışmaktadırlar. Bağımsız iş yeri açanların çoğu ise küçük esnaf niteliğindedir (Lordoğlu, 2015:425).

Türkiye'de esnaflık yaparak hayatını geçindiren Suriyeli oranı \%6,7'lik bir dilimdir. (Çetin, 2017: 1003). Mülteci veya göçmen girişimcilik, iş̧ kurma faaliyetinin göç edilen ülkede gerçekleştirilmesi, ekonomik değerin göçmenler eliyle gerçekleştirilmesi sürecidir (Nişancı, 2015: 6). Ülkemizdeki Suriyeliler, misafir olarak kabul edilmektedir. Sı̆̆ınmacı misafir, yerleşme amacı olmayan kişilerin bulundukları ülkeden başka bir ülkeye geçici bir süre için göç etmesi olayına denir. Türkiye'de ise misafir kavramı, "Geçici Koruma" rejimine tabi mültecileri ifade etmektedir (Sandal vd., 2016: 466). Suriyelilerin büyük çoğunluğunu kırsal ve alt gelir seviyesindeki kesimler oluştursa da başta Halep'ten olmak üzere yatırımcı ve tüccar kesimin de Türkiye'ye yerleştiği görülmektedir. Sermayesi olan Suriyeliler genellikle kayıt dışı olarak çeşitli iş kollarında işletmeler açmaktadırlar. Hatay, Antep önde gelen iller olsa da Mersin de öne çıkan iller arasındadır (Güler, 2017:1).

Suriyeliler, çoğunlukla esnaf girişimciliği yapmaktadırlar. Suriyelilerin açtığı işyerleri genelde; dükkânlar, fırınlar, market, kafe, dönerci, terzi, kuyumcu, küçük çaplı tekstil, takı toka, çanta, ikinci el eşya dükanı şeklindedir. Özellikle çay, kahve ve ekmek gibi temel ihtiyaç maddeleri Suriye'den getirilmekte ve ağırıkı olarak Suriyelilere hizmet vermektedir. Birçoğunun kaçak olması ve vergi vermemesine tanınan devlet imtiyazı, Suriyeli esnaf ile yerel esnaf arasında gerginlik yaşanmasının nedeni olmaktadır (ORSAM-TESEV, 2015:18; Lordoğlu, 2015:425).

Mersin merkez nüfusu 1 milyon, Suriyeli 300 bindir. Neredeyse her 3 kişiden 1'i Suriyelidir (MTSO, 2018). Mersin Esnaf ve Sanatkârlar Odası Birliği Başkanı Dinçer, 2016 yılı araştırmalarına göre Mersin'de 700'ün üzerinde Suriyeli Esnaf bulunduğunu belirtmektedir. Ancak bunun üç katı daha kayıt dışı işletme olabileceğinin tahmin edildiğini vurgulamaktadır. (Haberler.com 11Mayıs 2016). Var olan işsizlik ve esnaf sorunlarına ilaveten, Suriyeli işgücünün devreye girmesi ve artan bir şekilde Suriyelilerin esnaflı̆a başlaması nedeniyle, sorunlar daha karmaşık hale gelmektedir. Bu kapsamda, Türk esnafta Suriyeli esnafa karşı giderek daha olumsuz bir tutumun geliştiği, zaman zaman araştırmacıların gözlemi olmuștur. Bu nedenle, araștırmada Türk esnafın Suriyeli esnaf hakkında ne düşündüğü, olumlu veya olumsuz değerlendirmelerinin gerekçeleri, Suriyeli esnafın avantaj ve dezavantajları ile varsa işbirliği konuları belirlenmek istenmiştir.

Bir tarafta, iç savaş nedeniyle zorunlu göçmek ve yaşam mücadelesi vermek durumunda olan Suriyeli esnaflar, diğer taraftan eşit koşullarda rekabet ve kazanç sağlanmadığını düşünen yerel esnaf durmaktadır. Önümüzdeki on yıl içinde, Türkiye'nin en önemli sorunlarından birinin Suriyeliler ile yerel halkın yaşayabileceği toplumsal gerginlikler olacağı yönünde öngörüler bulunmaktadır (Erdoğan, 2015; Demir, 2016; Çetin, 2017). Bu ve benzeri araştırmalar gerginliğin boyutu hakkında bilgi verebilir ve çözüm merciini harekete geçirebilir. Nihai amacımız, sorun ve beklentilerden yola çıkarak, karşılıklı hoşgörü ve anlayışın gelişimine katkı sağlamak ve olası gerilimleri bugünden öngörmeye çalışarak karar alıııları harekete geçirmektir.

\section{LITERATURE INCELEMESi}

Yazında mülteci esnaf girişimciler (Çakıcı vd.2016; Çetin, 2017:), göçmen girişimciler (Nişancı, 2015;Subanova, 2013) üzerine araştırmalar yapıldığı görülmektedir. Türkiye İşveren Sendikaları Konfederasyonu, Türkiye'de iş dünyasının Suriyeliler konusunda görüş ve beklentileri üzerine kapsamlı bir araştırma yaptırmıştır (Erdoğan ve Ünver, 2015). Meslek odalarının basında yer alan birtakım değerlendirmeleri olmakla beraber, yerli esnafın, mülteci esnaf hakkında ne düşündüğü konusunda spesifik bir araştırmaya rastlanmamıştır.

\section{VERI VE YÖNTEM}

Keşifsel tarzda tasarımlanan araştırmada veriler, yüz yüze görüşme yoluyla elde edilmiștir. Görüşme formunun hazırlanmasında Suriyeli esnafla ilgili yapılan çalışmalardan (Çakıcı vd. 2016) yararlanılmışır. Araştırmanın genel evrenini Mersin merkezde bulunan Türk esnaf oluşturmaktadır. Türk esnafın tamamına ulaşmak zaman ve kaynak koşullarında zor olduğundan, araştırmacılarla işbirliği yapan, Türk esnafla görüşülmüştür. Mersin ilimizde Suriyeli iş yerleri, özellikle, Mezitli, Çamlıbel, Yeni Mahalle, Siteler, Gündoğdu, Yeni Pazar bölgelerinde yoğunluktadır. Bu nedenle veriler, ağırlıklı olarak bu bölgelerdeki Türk esnaflardan (2017 Nisan-Haziran) sağlanmıștır. Görüșme formu yüz yüze uygulanırken, gözlemler ve yapılan sohbetler not alınarak kayıt altına alınmıştır. Bu bilgiler bulguların yorumlanmasında kullanılmıștır. Uygulama dönemi sonunda 230 Türk esnafa ulaşılmış, ancak bunların 213'ü değerlendirilmiştir. Görüşmelerden elde edilen veriler içerik analizine tabi tutulmuş, kelime tekrar sayısından frekans dağııımları elde edilmiştir.

\section{BULGULAR}

\section{Katılımcılar Hakkında Bilgiler}

Araştırma yapılan Türk esnafın çoğunluğu erkek (\%90), üçte biri 22-35 yaş arası (Y kuşağı) ve \%47'si 36-50 yaş (X kuşağı) arasıdır. \%82'si lise ve altı eğitim düzeyindedir. İşletmelerin üçte biri 1999 yılı ve öncesinde, üçte ikisi ise 2000 ve sonrasında kurulmuştur. Yanlarında genelde 1 kişi (\%47) çalıştırmaktadırlar. 14 esnaf yanında 1 Suriyeli, 8 esnaf ise 2 Suriyeli çalıştırmaktadır. Bıçak bileme işinden çiçekçiye, elektrikçiden tüp gaz bayiine kadar hemen her kesimden esnaf ile görüşülmüştür. Görüşme yapılan esnafın 36'sı, "dönerci, tantunici, ciğerci, lokanta, ev yemekleri, çorbacı, çiğ köfteci, kafeterya" gibi işlerden birini yapmaktadır. 23'ü manav-bakkal, kasap-tavukçu, 22'si terzi-tadilatkonfeksiyon, 15'i kuyumcu-döviz bürosu, 13'ü aksesuar-çiçek-parfümeri, 11'i ayakkabı-çanta satışı türünden esnaftır. Arta kalan 93 esnaf ise farkıı işkollarındandır. 


\section{Mersin'deki Türk Esnafın Suriyeli Mülteci Esnafa i̇lişkin Görüşleri}

Türk esnafına yöneltilen, "Suriyeli mültecilerin Mersin'de iş kurma girişimlerini nasıl karşılıyorsunuz?" sorusuna çoğunluk olumsuz yaklaşmışır. Bir esnafın şu sözlerini, çoğu Türk esnaf paylaşmaktadır. "Suriyeli mültecilerin yanımızda, sağımızda, solumuzda, önümüzde, arkamızda, karşımızda iş kurmalarını çok hoş karşılamıyoruz". Katılımcıların 163'ü $(\% 76,5)$, Suriyelilerin esnaflığa başlamalarına olumsuz yaklaşmaktadır. 29'u (\%14) kişi olumlu görüşe sahiptir. 11 esnaf mecburlar demiş, 10 esnaf ise, kararsız kalmıştır. Bu 10 esnafın, 7'si olumsuz ifade kullanmıştır. Dolayısıyla olumsuz bakan esnaf sayısı 170'tir. Çizelge 1, Türk esnafın, Suriyeli esnaf hakkındaki düşüncelerinin dağııımını göstermektedir. 213 katılımcıdan 170'inin bakıs açısı olumsuz ifadelerden oluşurken, 43'ü olumlu ifadelerde bulunmuştur. Olumsuz görüşte olanların argümanları şunlardır: Suriyeli esnaf vergi vermemekte, odaya kayıt yaptırmamaktadırlar (\%19). Satışlarımız ve pazar payımız düşmüştür (\%13). Fiyatları düşürmekte, kalitesiz üretim yapmakta, piyasayı altüst etmektedirler (\%11). Suriyelilerin işyeri açmalarına tamamen karşı olan \%10'luk dilimin gerekçesi ise, devletten maaş almalarıdır.

Türk esnaf, işlerinin azaldığı ve işyeri kiralarının \%70 artığı, bunun da zaten zor olan durumlarını daha da zora soktuğunu sözlü beyan etmişlerdir. Bir esnaf "Kayıt dışılık, ucuz iş̧̧ilik ve malını Suriye'den ucuza getirerek, aynı ürünü çok ucuza verebilmekte bu da haksız rekabet yaratmaktadır. Küçük esnaf ya kepenk kapatmakta ya da kredilerle günü kurtarmaya çalışmaktadır".

\section{Çizelge 1. Türk Esnafın Suriyeli Esnaflara Dönük Olumsuz Düşüncelerinin Dağılımı}

\begin{tabular}{|c|c|c|}
\hline Olumsuz görüşler & $\mathbf{F}$ & $\%$ \\
\hline Vergi vermiyorlar, su-elektrik ödemiyorlar, vergiye tabi olsunlar, oda üyelikleri yok & 32 & 18,8 \\
\hline Rekabeti artırdılar, satışlar düştü,kar marjları düştü, pazar payı azaldı & 22 & 12,9 \\
\hline Düşük fiyat, düşük nitelik, ucuz-kaçak işçi & 18 & 10,6 \\
\hline İş yeri açmasınlar, devletten maaş alıyorlar, hatalı-mantıksız bir karar, zaten insanlar zor durumda & 13 & 7,6 \\
\hline Çok rahatlar, kontrolsüz yaşıyorlar, uyumsuzlar & 11 & 6,5 \\
\hline Satışlar-kar marjı düştü, pazar payı küçüldü & 11 & 6,5 \\
\hline Onlara verilen destek, Türklere verilmiyor; daha avantajılar & 9 & 5,3 \\
\hline Haksız rekabet, kayıt dışılık arttı & 7 & 4,1 \\
\hline İşsizliği artırdılar, ucuz işgücü sağladılar & 7 & 4,1 \\
\hline Kendimizi güvende hissetmiyoruz, kendi memleketimizde yabancı olduk & 6 & 3,5 \\
\hline Kiralar yükseldi & 6 & 3,5 \\
\hline Olumsuz, görüş belirtmemişler & 6 & 3,5 \\
\hline Birbirlerini kolluyorlar & 5 & 2,9 \\
\hline Türk esnafını öldürdüler, bitirdiler & 5 & 2,9 \\
\hline Çok amatörler, çok cesurlar, çok sorun çıkarıyorlar, öğrenmeden iş yapıyorlar & 4 & 2,4 \\
\hline Belediye, maliye, emniyet bizi sıkıştırıyor; onları es geçiyor & 4 & 2,4 \\
\hline Kendilerini kolluyorlar & 2 & 1,2 \\
\hline Yaşam standardımız, gelirimiz düştü; bizden daha iyi yaşıyorlar & 2 & 1,2 \\
\hline Toplam & 170 & 100,0 \\
\hline
\end{tabular}

Bir başka esnaf "Dürüm fiyatı, Türk esnaflarında 6 TL ise, Suriyeli esnaflar piyasa fiyatını kırarak yarı fiyatına satıs yapmaktadırlar. Türk müşteriler değişik damak tadı almak ve daha ucuza doymak adına Suriyeli esnaftan yemek yemeyi tercih etmektedir". Diyerek piyasayı fiyat ve nitelik olarak düşürdüklerini ileri sürmüştür. Türk esnaf kuyumcularla yapılan sohbetler sırasında, Suriyeli kuyumcu esnafların 21 ayar altın satarak piyasada kafa karışıklığına sebep olduklarını ve iş̧̧ilik ücreti almadan veya cüzi bir miktar alarak altın satışı yaptıklarını, bu nedenle müşterilerin Suriyelileri tercih ettiklerini dile getirmiştir.

Türk terzi esnaflarla yapılan sohbetler sırasında Suriyeli mültecilerin hemen her işe el attıklarını ifade etmişlerdir. Bir terzi "özellikle de terzilik ve tadilat işlerinde örneğin pantolon paçasını biz Türk esnafı 5 TL'ye yaparken Suriyeli esnaf yarı fiyatına yapmaktadır, dolayısıyla müşterilerimiz gittikçe azalmaktadır", diyerek kayıt dışılık ve ucuz işçiliğin sağladığı düşük maliyetlerde onlarla yarışamadıkları belirtmişlerdir. Ayrıca Suriyeli mültecilerin iş kurma girişimlerinin var olan işsizliği artırdığı, çalışıırdıkları kişilerin çoğunlukla Suriyeliler olduğu, alış veriş ve istihdam konusunda birbirlerini kolladıkları belirtilmiştir. Suriyeli Mültecilerin iş kurmalarına tamamen karşı olanların düşüncesini bir Türk esnaf şu şekilde ifade etmiştir. "Kendi ülkemizde Suriyeli mültecilerin Türk esnaflardan rahat yaşamaları, bir problem yaşamadan işletme kurmaları ve Suriyeli mültecilere işletme kurma gibi haklar verilmesi bizim zorumuza gidiyor. Bu durum, Türk esnaf işletmelerini oldukça etkilemektedir. Suriyeli mülteciler gelişi güzel her işi yapmaya kalkısııyorlar ve Suriyeli esnaf sayııı sürekli artıyor. Kendi ülkemizde yabancı gibiyiz".

Diğer yandan, Suriyeli esnafların vergi ödemedikleri, ruhsatsız işletme kurdukları, yanlarında çalıştırdıkları personele maaş vermedikleri veya çok az verdikleri, SGK ve Bağ-Kur ödemesi yapmadıkları için karlarının ceplerinde kaldığı, bu durumun da haksız rekabete sebep olduğu yaygın bir görüştür. Ayrıca Suriyeli mülteci esnafların piyasanın kalitesini düşürdüğü görüşünü taşıyanlar da vardır.

Çizelge 2 Türk esnafların Suriyeli esnaflara ilişkin olumlu görüşlerinin dağıımını göstermektedir. 43 Türk esnaf, mültecilerin iş kurma girişimleri konusunda olumlu bakış açııına sahiptir. Olumlu düşünenlerin argümanları şunlardır: Yaşam mücadelesi veriyorlar (\%47), 
piyasayı canlandı, alışveriş arttı, tüketim arttı (\%33), herkes iş kurabilir, herkes rızkını yer, rızkı Allah verir (\%9). Olumlu görüşe sahip Türk esnaf yapılan görüşmelerde, Suriyeli mültecilerin esnaflı̆a başlamalarında sakınca görmediklerini, kendi geçimlerini ve ekmeklerini kazanmaya çalışııları dolayısıyla kendi işyerlerini kurmalarının mantıklı olduğunu, aksi takdirde asalak bir şekilde yaşamak zorunda kalacaklarını ve hırsızık, yankesicilik gibi yasadışı işler yapacakları yönünde görüş belirtmişlerdir. Ayrıca, mülteci yatırımcıların piyasaya girmesinin ekonomiyi az da olsa canlandırdığı düşünülmektedir.

Çizelge 2. Türk Esnafın Suriyeli Esnaflara Dönük Olumlu Düşüncelerinin Dağıımı

\begin{tabular}{|l|l|l|}
\hline Olumlu görüşler & F & $\%$ \\
\hline Yaşam mücadelesi veriyorlar, ekonomik özgürlüklerini elde etsinler & 20 & 46,5 \\
\hline Piyasa canlandı, alışveriş arttı, tüketim arttı, müşteri sayısı arttı & 14 & 32,6 \\
\hline Herkes iş kurabilir, herkes rızını yer, rızkı Allah verir & 4 & 9,3 \\
\hline Olumlu, ancak görüş belirtmemişler & 4 & 9,3 \\
\hline Ürünlerde farklııı, çeşitlilik yaratıyorlar & 1 & 2,3 \\
\hline Toplam & 43 & 100,0 \\
\hline
\end{tabular}

\section{Türk Esnafa Göre Suriyeli Esnafın Avantaj ve Dezavantajları}

Türk esnaflara, Suriyeli esnafların yarattığı avantaj ve dezavantajların neler olduğu sorulmuştur. Bu soruya 177 esnaf yanıt vermiştir. Yanıt veren Türk esnafın 37'si (\% 21) Suriyeli esnafın kendileri açısından avantaj yarattığını belirtmiştir. Bu avantajlar içinde ucuz işgücü sağlamaları ve piyasanın canlanması öne çıkmaktadır. Türk esnaflardan bir kısmı, şu anda Türk ekonomisinin giderek kötüleştiğini ve piyasada dönen paranın Suriyeli mültecilerin nakit parası olduğunu, bu durumun ekonomiyi olumlu bir şekilde etkilediğini belirtmiştir. Ayrıca altın ve gıda sektöründe kendi aralarında toptan alış-veriş yaptıklarını, Suriyeli mülteciler ve esnaflar sayesinde müşteri potansiyellerinin arttığını belirten esnaflar da olmuştur. Bir başka avantaj, Suriyeli mültecilerin esnaflığa başlamaları sebebiyle bazı Türk esnafların Suriyelilere dükkânlarını ve evlerini kiraya vermeleri hususudur. Atıl duran iş yerleri değer kazanmıştır. Ancak bu avantaj kiraya verecek ev ve işyeri olan esnaflar için geçerli iken, olmayan esnaf için, yüksek kira bedeli ödeme zorluğu anlamına gelmektedir.

Bunların aksine, Suriyelilerin esnaflığa başlamalarının avantaj veya dezavantajları sorusunda yanıt verenlerden 140 (\%79) Türk esnaf, Suriyeli esnafın kendileri açııından dezavantaj oluşturduğu kanaatindedir. Bu dezavantajlar arasında; satışların ve kar marjının düşmesi başta gelmektedir (\%31), uyumsuz olmaları (\%13), kiraların yükselmesi (\%12), fiyat kırmaları (\%9), birbirlerini kollamaları (\%9) gelmektedir. Ayrıca vergi ödememeleri, işsizliği artırmaları, kaçak mal satmaları, devletin örtük imtiyazı nedeniyle dezavantaj yaratıldığı görüşündedirler.Satışlarının düşmesini bir esnafın şu sözleri aydınlatmaktadır. "Mülteciler ilk geldikleri yıllarda alışverişlerini sürekli olarak Türk esnaflardan yaptılar. Suriyeli mültecilerin esnaflığa başlamalarıla, Suriyelilerin Türk esnaflardan alış veriş yapma oranlarını giderek düştü".

Suriyeli esnaf mültecilerin ucuza mal satmaları, ucuz iş̧ilik ve devletin onlara sağlamış olduğu birtakım avantajlar sayesinde, Türk esnafından bir adım önde olduklarını, herhangi bir planlama yapmadan gelişi güzel ticari işletme kurduklarını ve bazı kişilerin başarısız olduğu için işletmelerini sürekli olarak kendi aralarında birbirlerine devrettikleri ara sohbetlerde dile getirilmiştir. Türk esnafların en önemli şikayetlerinden birisi, Suriyeli esnafların piyasayı fiyatlarını sürekli olarak düşürmeleri nedeniyle kendi müşterilerinin azalmasıdır.

\section{Türk Esnaf ve Suriyeli Esnaf İşbirliği}

"Suriyeli esnafla herhangi bir konuda işbirliğiniz oldu mu?” sorusuna araştırmaya katılan 213 Türk esnaftan 27'si Suriyeli esnaf ile işbirliği yaptığını söylemiş̧ir. Suriyeli mülteci esnafların yurt dışından uygun fiyatlı ürünler getirdikleri ve getirmiş oldukları ürünleri toptan fiyattan Türk esnaflara satmaya çalıştıkları ve Türk esnaflarımızın fiyat uygunluğundan dolayı Suriyeli esnaf girişimcilerle ara ara mal alımı ve satımı konusunda işbirliği yaptıkları anlaşılmıştır. Ayrıca bazı esnaflar, Suriyeli eleman çalışırdıklarını ve Suriyeli mültecilere ev ve dükkânlarını kiraya verdiklerini belirtmişlerdir. Türk esnafların ise Suriyeli mültecilere tercümanlık yapma konusunda yardımcı oldukları dile getirilen bir diğer dayanışma şeklidir.

Ayrıca Türk esnaflara, Suriyelilerin ülkelerine dönmelerini isteyip istemedikleri sorulmuştur. Katılımcıların \%85'i evet, \%10'u hayır, \%5'i ise kararsız olduğunu ifade etmiştir. Bu bulgu, "olumsuz tutum" içinde olduklarını göstermektedir.

\section{SONUÇ}

Sonuç olarak Mersin'deki Türk esnafların Suriyeli Esnafların iş kurma girişimlerine karşı tutumu pek olumlu değildir. Suriyeli esnafların ruhsat almadan dükkân açtıkları, vergi ödemedikleri, elektrik su ücreti ödemedikleri, devletin Suriyeli mülteci esnaflara imtiyazlı davrandığı ve Suriyeli esnaflara gösterilen özel koşulların Türk esnafa sağlanmadığı, ucuz iş̧̧ilik ve ucuza ürün üretip sattıkları için haksız rekabetin olduğu, yaygın görüş olarak belirlenmiştir. Mersin'deki Türk esnaf, AVM ve süpermarketlerle rekabet edemezken, Suriyeli mülteci esnafın daha avantajlı iş yeri açmasından huzursuzluk duymaktadır.

Araştırmamıza göre, Suriyelilerin iş kurma girişimlerini olumlu karşılayan Türk esnaf bunu, onların yaşam mücadelesi vermeleri, piyasayı canlandırmaları ve ucuz iş̧̧ilik sağlamalarıyla açıklamaktadırlar. Çoğunluk, Suriyeli esnafın kendileri açısından dezavantaj oluşturduğu fikrine sahiptir. Çok küçük bir kesim Suriyeli esnaflarla işbirliği yaptığını belirtmiştir.

Yapılan araştırmalara (Erdoğan ve Ünver, 2015; Erdoğan, 2015; Sandal vd. 2016; Çetin, 2017) paralel olarak bu araştırmada da ortaya çıkan, mevzuata uygun biçimde açılan iş yerlerinin, kayıt dışındakilerin haksız rekabetinden ciddi bir biçimde etkilendikleri ve bu durumun kızgınık boyutunda olduğudur. Suriyelilerin entegrasyonu konusunda birçok araştırması olan Erdoğan ve Ünver (2015: 78), bu durumun bazı 
bölgelerarası dengesizliklere bile neden olabildiğini vurgulamaktadırlar. Örneğin Denizli esnaf ve sanayicisi, geleneksel olarak rekabet içinde oldukları Gaziantep'in Suriyeliler sayesinde düşük maliyet imkanına kavuştuğunu ve artık Gaziantep'le rekabet edemediklerini ifade etmişlerdir. Netice itibariyle kayıt dışılık hem kurallara uygun çalışan işletmeleri, hem devleti, hem de istismara açık emek gücünü tehdit etmektedir.

Dolayısıyla ne yapmak gerekmektedir? Suriyelilerin ekonomik ve toplumsal entegrasyonu konusunda; ILO Türkiye Ofisi, AFAD, Göç İdaresi, TiSK, ORSAM, TESV gibi bazı kurum ve kuruluşların araştırma yaptıkları, raporlar düzenledikleri ve çeşitli öneriler geliştirdikleri görülmüştür. Ancak, bunlar somut uygulamalara ve politikalara dönüştürülemediği anlaşılmaktadır.

Erdoğan ve Ünver'e göre (2015: 81), devletin farklı kurumlarının Suriyelilerin geleceği konusunda ciddi analizlere ve geleceğe yönelik projeksiyon çalışmalarına ağırlık verilse de, Türkiye'de siyasetin ve devletin Suriyeliler konusunda gerçekle yüzleşmesinde ve bunu kamuoyu ile paylaşmasında bir çekingenlik dikkati çekmektedir. Lordoğlu (2015:428) önlemlerin merhamet ve yardım çerçevesinde kaldığını eşit haklara sahip olmadıkça çatışmaların süreceğini ileri sürmektedir.

Bununla birlikte, Türkiye'deki Suriyeliler konusunda Türk toplumunun, bütün kaygılarına, şikayetlerine ve itirazlarına rağmen, toplumsal kabul düzeyi son derece yüksektir. Ancak bu durumun ne kadar sürdürülebilir olduğu tartışmalıdır (Erdoğan ve Ünver, 2015: 87). Nitekim 2016 Mayıs ayında Mersinde Suriyeli esnaflar üzerinde yapılan araştırmada (Çakıcı vd. 2016), Suriyeli esnaf, çoğunlukla Türk esnafın iş kurma girişimlerini olumlu karşıladıklarını belirtmiştir. Ancak, bir yıl sonra yapılan bu araştırma Suriyeli esnaf sayısının giderek artması, çoğunun kayıtsız olması, alış verişi birbirlerinden yapmaları, devletin Suriyeli mülteci esnafa daha imtiyazlı/hoşgörülü davranması, haksız rekabet yaratmaları, dükkan kiralarında iki katı artışa neden olmaları olumlu görüşü tersine çevirmiştir. Araştırmaya katkı sunan bir Türk esnafın tabiriyle; "2017 yılında gelirlerin düşmesi, nakit sıkıntısı, likidite sıkıntısı, aşırı vergi yükünün Türk esnafına yüklenmesi, işlerin durgunluğu sebebiyle kazanç dengesizliğinin oluşması, piyasada iç satışların düşmesi esnafın borçlarını ödeyemez hale gelmesi gibi yaşanan olumsuzluklar, Suriyeli esnaf meselesini Türk esnafın gözünde daha da ağırlaştırmaktadır".

Ekonomi çevreleri çözümün siyasi irade gerektirdiğini ve ancak siyasi adım atıldıktan sonra stratejik planlama, politika yapım sürecine destek verebileceklerini belirtmişlerdir (Erdoğan ve Ünver, 2015: 69-70). Kanımızca, Suriyeli sığınmacıların geçici korumada olduğu, bir gün dönecekleri düşüncesi ile somut çözümler üretme yerine durumu idare etme yolu seçilmekte, bütünsel bir strateji geliştirmede bilim, siyaset, sanayii işbirliği sağlanamamaktadır. Ancak altı yıl geçti ve Suriyelilerin geri dönüş umudu zayıf görünmektedir. Giderek Türk esnaf ile Suriyeli esnaf arasındaki gerilimin artacağı, çözümün siyasi iradede olduğu anlaşılmaktadır.

\section{KAYNAKLAR}

Çakıcı, A., Yılmaz, Ş., Çakıcı, C. (2016). Mülteci esnaf sorunları: Mersin'deki Suriyeli esnaflar üzerinde bir araştırma. ICOMEP/ProceedingsBook.

Çetin, ì. (2017). Suriyeli mültecilerin işgücüne katılımları ve entegrasyon: Adana-Mersin örneği. http://dergipark.gov.tr/download/articlefile/231701.

Demir, A. O. (2016). Suriyeli mülteciler için doğru çözümleri bulabilecek miyiz?. Ekonomistler Platformu, http://www.ekonomistler.org.tr/arsivler/4667 (Erişim:16. 01.2018)

Erdoğan, M. (2015). Türkiye'deki Suriyeliler: toplumsal kabul ve uyum. Bilgi Üniversitesi Yayınevi, İstanbul.

Erdoğan, M., Ünver, C. (Kasım 2015). Türk iş dünyasının Türkiye'deki Suriyeliler konusundaki, görüş, beklenti ve önerileri. http://tisk.org.tr/tr/e-yayinlar/353-goc/353-goc.pdf

Güler, R. (6 Mart 2017). Suriyelilerin sosyal ve ekonomik entegrasyonlarında sorunlar ve çözüm önerileri. http://sahipkiran.org/2017/03/06/suriyelilerin-entegrasyonu/

https://www.haberler.com/mersin-dincer-suriyeli-aciyor-turk-esnaf-kepenk-8427763-haberi/ (11Mayıs 2016).

ILO (2016). Suriyeli işçi, işveren ve girişimcilerin işgücü piyasasında karşılaştıkları sorunlar ve çözüm önerileri çalıştayı genel değerlendirme. (13 Haziran 2016). ILO Türkiye Ofisi ve Suriye Dostluk Derneği, http://www.ilo.org/ankara/news/WCMS_493930/lang--tr/index.htm

Lordoğlu, K. (2015). Beş sınır kenti ve işgücü piyasalarında değişim: 2011-2014. Turkish Migration Conference 2015 SelectedProceedings. Ss.421-431.

MTSO. (2018). http://www.mtso.org.tr/tr/haberler/mersin-suriyeli-gocmen-sorununa-cozum-ariyor (Erişim 16.01.2018).

Nişancı, Z.N. (2015). Göçmen girişimcilik üzerine Pittsburgh'daki Türk girişimciler. Girişimcilik ve Kalkınma Dergisi. Cilt 10, Sayı 1, ss 1-28.

ORSAM-TESEV (2015). Suriyeli sığınmacıların Türkiye'ye etkileri. ORSAM 8Ortadoğu Stratejik Araştırmalar Merkezi) Rapor No: 195, (Haz: O.Orhan, S. SenyücelGündoğar) ss1-40, http://tesev.org.tr/wp-content/uploads/2015/11/.

Sandal, E. K.,Hançerkıran, M., Tıraş, M. (2016). Türkiye'deki Suriyeli mülteciler ve Gaziantep ilindeki yansımaları. Gaziantep UniversityJournal of SocialSciences (http://jss.gantep.edu.tr) 15(2):461-483, ISSN: 2149-5459.

Subanova, A. (2013). Türkiye'deki Kırgız ve Kazak kökenli göçmen girişimciler üzerine bir alan araştırması. (Yayımlanmamış yüksek lisans tezi). Hacettepe Üniversitesi Sosyal Bilimler Enstitüsü. Ankara. ss. 1-91. 